\title{
Proposta de um Jogo Educacional para alfabetização de crianças com dislexia
}

\author{
Jucelio Soares dos Santos ${ }^{1}$, Rodrigo Alves Costa ${ }^{1}$, Rakel Pereira de Souza ${ }^{1}$, Isolda \\ Bezerra Pereira $^{1}$, Rafaela Samara Oliveira Pereira ${ }^{1}$
}

\author{
${ }^{1}$ Universidade Estadual da Paraíba \\ jucelio.soares.santos@gmail.com, rac2@cin.ufpe.br, \{rakelsouza7, \\ isoldapereira2, rafaelasamara.cdc\}@gmail.com
}

\begin{abstract}
The aim of this paper is to report the conception of an educational game for the teaching of dyslexic children during the stage of literacy, as a support tool in the process of acquisition of reading and writing skills. The main results of this work are: an analysis through bibliographical study about the teaching and learning process of children with dyslexia disorder in the school literacy stage; the analysis of some existing educational software geared towards improving the acquisition of reading and writing; the analysis of the literature for dyslexic students at the stage of literacy and the educational game design which specifies, in detail, the structure and the functioning of the entire game.
\end{abstract}

Resumo. $O$ objetivo deste trabalho é relatar o desenvolvimento da concepção de um jogo educacional para o ensino de crianças disléxicas na fase de alfabetização, a ser utilizado como uma ferramenta de apoio no processo de aquisição da leitura e da escrita. Os principais resultados deste trabalho são: a análise por meio de estudo bibliográfico sobre o processo de ensinoaprendizagem em escolares na fase de alfabetização que apresentam o distúrbio de dislexia; a análise de alguns softwares educacionais existentes para melhorar a aquisição da leitura e da escrita; a análise da literatura sobre softwares educacionais para alunos disléxicos na fase de alfabetização e a concepção do jogo educacional que se especifica, detalhadamente, a estrutura e todo o funcionamento do jogo.

\section{Introdução}

No Brasil, um dos principais fatores que levam as crianças a terem dificuldades durante o processo de alfabetização nas escolas é o distúrbio de aprendizagem. Grande parte destas crianças provavelmente irá desistir da vida escolar em algum momento, sendo que mais de $40 \%$ dos alunos possuem dificuldades relacionadas ao domínio da leitura e escrita. Entre os distúrbios existentes, podemos destacar a dislexia, que vem sendo detectada no interior da escola durante o processo de alfabetização [Zorzi 2003].

A dislexia não se trata especificadamente de uma doença, mas de um distúrbio genético-neurológico que afeta entre três e dez por cento da população mundial. Tem origem por causa hereditária e se caracteriza como uma dificuldade em fazer cálculos mentais, organizar tarefas diárias e lidar com noções de tempo e espaço. Tornando a aprendizagem da leitura e escrita inconstante, causando dificuldades na soletração de palavras.

A partir da condução sobre uma avaliação e os processos de intervenção em tal 
distúrbio, como a prática fônica e a metafonológica, é possível instrumentalizar e conduzir o aluno durante o processo de alfabetização, amenizando a influência das dificuldades em atividades relacionadas a leitura e a escrita.

Em paralelo, a ciência da computação tem apresentado a possibilidade de utilizar suas tecnologias como ferramentas de ensino e aprendizagem, que abrangem as potencialidades do lúdico. Aprimoradas pela técnica e pela possibilidade de autoria, essas ferramentas permitem a experimentação e a construção do conhecimento de forma desafiadora, criativa e prazerosa. Embora exista, de fato, uma grande variedade de softwares produzidos no mercado para a educação, infelizmente poucos estão aptos a serem utilizados no apoio aos alunos disléxicos em sala de aula, já que a maioria não apresenta funcionalidades específicas para a prática de leitura [Pinto e Botelho 2012]. Devido a essa carência, identificamos por meio desta pesquisa a necessidade de endereçar ferramentas educacionais adequadas a esse público específico. Então, objetivamos a desenvolver uma concepção de um jogo educacional para o ensino de crianças disléxicas na fase de alfabetização, a ser utilizado como uma ferramenta de apoio no processo de aquisição da leitura e da escrita.

\section{Metodologia}

A partir do objetivo desta pesquisa, foi conduzido um levantamento bibliográfico sobre o tema abordado, esse estudo relatou como se aplica a condução de softwares educacionais (SE) aptos para o processo de ensino-aprendizagem em escolares disléxicos. Realizamos uma análise destas ferramentas para proporcionar maior familiaridade com o problema investigado, a fim de torná-lo explícito, caracterizando como uma pesquisa exploratória [Gil 1991], visando o aprofundamento no estudo sobre a dificuldade enfrentada na escolarização de alunos disléxicos.

Do ponto de vista da natureza da pesquisa, este trabalho se classifica como uma pesquisa aplicada (ou tecnológica), que tem por objetivo gerar produtos ou processos, com finalidades imediatas, com base em conhecimentos prévios [Jung 2004]. O processo pretendido é desenvolver um protótipo de um SE para o ensino de alunos com dislexia na fase de alfabetização.

\section{Processo de aquisição da linguagem em disléxicos}

Prevalecem nos problemas de aprendizagem nas escolas, os que configuram diferentes tipos de distúrbios referentes à evolução da linguagem especificadamente no plano da oralidade e, constantemente no domínio da leitura e escrita. Os problemas de aprendizagem relacionados a alterações na linguagem são distúrbios que afetam o desenvolvimento de habilidades linguísticas fundamentais no processo de alfabetização [Zorzi 2003]. Na dislexia essa dificuldade se manifesta em diferentes formas de linguagem, além dos problemas com a leitura, outro problema óbvio está na aquisição da proficiência em atividades relacionadas à ortografia e escrita. Problemas com leitura e ortografia são as principais dificuldades em termos de habilidades acadêmicas relacionadas à dislexia [Fletcher et al. 2009].

Para adquirir habilidade na leitura e ortografia, o disléxico precisa desevolver a linguagem, e para adquiri-la são necessárias ações construtivas através de interações sociais, para permitir a organização do cérebro para estabelecer uma conexão em um sistema complexo de linguagem. Os símbolos presentes na linguagem, por sua vez, são 
compostos de três partes: o som, o significado e a aparência do símbolo. Como alguns símbolos são aparentemente próximos, observa-se que os disléxicos, quando iniciam o processo da leitura, confundem constantemente uma letra com a outra, apresentando dificuldades em decifrar o som e também de entender o seu significado.

Para [Schirmer, Fontoura e Nunes 2004] é por meio de estímulos da língua que podemos verificar a intensificação dos componentes do sistema de linguagem, o que ocorre de modo distribuído, geralmente automatizado e inconsciente. Envolve também o desenvolvimento de quatro sistemas interdependentes: pragmático; fonológico; semântico e gramatical. As crianças que possuem dislexia não conseguem atingir um nível satisfatório nessas atividades. Assim, se não diagnosticada e intervinda, a criança passa a ter comprometimento em atividades no reconhecimento da escrita e da compreensão da leitura. Como consequência dessa necessidade, a condução sobre a avaliação e os processos de intervenção em tal distúrbio de leitura tornou-se essenciais. Apesar de requererem muito esforço, os processos devem ser trabalhados na fase em que a criança começa o desenvolvimento da leitura e da escrita, principalmente durante a alfabetização.

Conforme [Capellini 2004], o diagnóstico deve ser realizado a partir de procedimentos que permitem definir qual nível funcional de leitura de cada criança. Tal observação permitirá orientar pais, professores e pacientes na escolha de uma intervenção adequada, estimulando estratégias para melhorar a utilização das habilidades e funções linguísticas e no desempenho em atividades escolares associadas à escrita e a leitura com intuito de superar as dificuldades.

$\mathrm{Na}$ medida em que os estudos de linguagem de compreensão da dislexia avançam, surgem também métodos revolucionários que colaboram na intervenção em escolares disléxicos. A partir da identificação do problema, situar e avaliar o desempenho escolar dessas crianças constitui ações que permitem diminuir e até mesmo prevenir os impactos sobre as dificuldades presentes na leitura e na escrita.

A intervenção, após o diagnóstico, é uma das principais formas de contribuição para diminuir os impactos psicológicos relacionados à dislexia, tornando-se uma medida na qual a criança passa adquirir confiança própria e auto estima. Conforme [Schirmer, Fontoura e Nunes 2004] há algumas atividades que podem ser incentivadas na criança a partir do envolvimento da linguagem escrita: i) Instigar a exploração e a aplicação do raciocínio de sua consciência na elaboração de sentença e textos e na formação de fonemas; ii) Proporcionar ocasiões para a escrita e leitura automáticas; iii) Investigar frequentemente as distintas atividades da escrita; iv) Esclarecer os contrastes presentes entre a língua falada e a escrita, abordando a adequação da criança mediante a consciência de que a fala e a escrita são distintas formas de se expressar por meio da linguagem.

Além dessas, existem outras atividades, formalizadas em métodos de intervenção que resultam em particularidades específicas no aprender sistemático de cada criança. Não existe unanimidade entre os especialistas em adotar um método específico para intervenções em escolares com dislexia. No entanto, podemos destacar os seguintes métodos existentes: Distema; Orton-Gillingtam; Impressão Psiconeurológica; Quinestéticos; Perceptivo-Motor; Fônico e o Multissensorial. Aliadas a esses métodos, o uso das tecnologias de comunicação e informação (TIC) tornou-se presente em intervenções durante o processo de alfabetização em alunos que possuem 
dislexia, a seguir será detalhado o uso dessas tecnologias.

\section{O uso das TIC para auxiliar a alfabetização de escolares disléxicos}

São inúmeros os benefícios que as TIC trazem à escola. De maneira geral, os estudantes se sentem mais motivados e concentrados, interagindo mais com o professor, o conteúdo passa a ser transmitido e atualizado rapidamente e, em alguns casos, se percebe uma redução nos índices de evasão escolar [Silva, 2013]. Dessa forma, o uso das TIC possibilita a integração de pessoas com limitações ao acesso da informação, surgindo como meio estruturado para diminuir desigualdades sociais.

Com intuito de intermediar as crianças com dificuldades de leitura e escrita, as TIC são fortes aliadas para criar habilidades em tais atividades, reforçando a aprendizagem de forma estruturada e multisensorial. Através delas é possível que a criança revise constantemente um assunto, além de proporcionar um trabalho individual com o ritmo do aluno.

Para [Amaral e Costa 2011], por meio de ferramentas como software, é possível que o indivíduo faça uso de diferentes atividades, estimulando o desenvolvimento das habilidades cognitivas e emocionais. O software surge, dessa forma, como um instrumento facilitador no processo de construção do conhecimento pelo disléxico. Porém, a escolha dessas ferramentas deve ser consciente para que haja $o$ desenvolvimento da pessoa com necessidade educacional especial, para que assim elas passem a reconhecer suas dificuldades e potencialidades e fazer o pleno uso dessas últimas. Como a maioria dos SE são produzidos no mercado com objetivos definidos por este, para atender as necessidades dos usuários em interagir, criar e modificar conteúdo, levando em consideração qual tecnologia específica será ideal para atingir os objetivos do indivíduo ou grupo que irá utilizá-lo.

Devido a variedade de recursos disponíveis no mercado atualmente, educadores sentem dificuldades na escolha de qual ferramenta utilizar em suas aulas. Apesar de não existir uma categorização entre os SE, há sempre um conjunto de características que definem se software é ou não adequado para uma ação pedagógica. E, se tratando de software com finalidade educacional é sempre necessário observar o público-alvo ao qual vai ser destino o seu uso. Além disso, para utilizar ferramentas na representação do conteúdo é imprescindível que esta estimule a criatividade, imaginação, o raciocínio, o trabalho em grupo e o mínimo de envolvimento entre o usuário com a ferramenta [Valente 1999].

\section{Estado da Arte Prática}

A partir de uma pesquisa baseada principalmente, na Internet, foi possível encontrar informações sobre jogos destinados a alfabetização de crianças com dislexia, cujos propósitos eram semelhantes ao da concepção de jogo. Os jogos a seguir foram indicados por associações como [ABD 2012] e o [Instituto ABCD 2014] que lidam com a dislexia e reconhecidas nacionalmente.

Com base no estudo bibliográfico, foram identificados alguns requisitos de alto nível relevantes para o desenvolvimento da concepção do jogo educacional e a partir de uma análise foi possível verificar que estas ferramentas possuem poucas adaptações. $\mathrm{Na}$ Tabela 1 apresentamos o resumo desta pesquisa, nesta tabela existe uma relação entre os 
requisitos de alto nível traçados com as ferramentas selecionadas para análise, indicando se o requisito foi atendido ou não.

Tabela 1 - Resumo da análise de aplicações existentes no mercado

\begin{tabular}{|c|c|c|c|c|}
\hline REQUISITO & ARAMUMO & $\begin{array}{l}\text { ARQUEIRO } \\
\text { DEFENSOR }\end{array}$ & $\begin{array}{l}\text { MIMOSA } \\
\text { E O } \\
\text { REINO } \\
\text { DAS } \\
\text { CORES } \\
\end{array}$ & $\begin{array}{c}\text { PLUCK } \\
\text { NO } \\
\text { PLANETA } \\
\text { DOS } \\
\text { SONS } \\
\end{array}$ \\
\hline $\begin{array}{l}\text { 1. Destinar-se } \\
\text { desenvolvimento de habilidades } \\
\text { voltadas para leitura e escrita, através } \\
\text { de atividades lúdicas e de caráter } \\
\text { educacional; }\end{array}$ & A & A & A & A \\
\hline $\begin{array}{l}\text { Estimular a exploração e a } \\
\text { aplicação do raciocínio de sua } \\
\text { consciência na elaboração de sentença } \\
\text { e textos e na formação de fonemas; }\end{array}$ & AP & $\mathrm{N}$ & A & A \\
\hline $\begin{array}{l}\text { 3. O conteúdo do jogo deve ser } \\
\text { voltado par dividir e manusear a fala } \\
\text { em suas distintas unidades - palavras, } \\
\text { sílabas e fonemas; }\end{array}$ & AP & $\mathrm{N}$ & A & A \\
\hline $\begin{array}{l}\text { 4. Fornecer o feedback ao aluno } \\
\text { sobre seu desempenho a partir da } \\
\text { investigação das distintas atividades } \\
\text { voltadas para leitura e escrita no jogo; }\end{array}$ & $\mathrm{AP}$ & $\mathrm{N}$ & $\mathrm{AP}$ & AP \\
\hline $\begin{array}{l}5 . \quad \text { O escopo do jogo deve incluir } \\
\text { atividades que estimulem a conexão } \\
\text { semântica e sintática de pronunciados, } \\
\text { incluindo a semelhanças do som entre } \\
\text { palavras e selecionar palavras que } \\
\text { estabeleça contraste entre os } \\
\text { significados e significantes; }\end{array}$ & A & NA & A & A \\
\hline $\begin{array}{l}6 . \quad \mathrm{O} \text { jogo deve exigir muita } \\
\text { atenção das crianças para contribuir na } \\
\text { capacidade de combinar elementos e na } \\
\text { concentração; }\end{array}$ & A & A & A & A \\
\hline $\begin{array}{l}7 . \quad \text { Esclarecer os contrastes } \\
\text { presentes entre a língua falada e a } \\
\text { escrita. Abordando a adequação da } \\
\text { criança mediante a consciência de que } \\
\text { a fala e a escrita são distintas formas de } \\
\text { se expressar por meio da linguagem; }\end{array}$ & AP & NA & A & NPA \\
\hline $\begin{array}{l}\text { 8. Estar baseado com uma das } \\
\text { especificações da BDA que o software } \\
\text { deve maximizar e treinar o uso do } \\
\text { teclado; }\end{array}$ & A & $\mathrm{AP}$ & NA & AP \\
\hline $\begin{array}{l}\text { 9. Ser disponibilizado de forma } \\
\text { livre para utilização; }\end{array}$ & A & A & A & $\mathrm{N}$ \\
\hline $\begin{array}{l}10 . \quad \text { Ser disponibilizado no idioma } \\
\text { Português Brasileiro; }\end{array}$ & A & A & A & A \\
\hline
\end{tabular}

Fonte: Criado pelos autores (2014). 
A partir desse estudo percebemos que, apesar de existirem poucas ferramentas aptas para o ensino de crianças com dislexia, atualmente não há ferramentas que atendam completamente os requisitos levantados anteriormente. Percebe-se com isso que há uma necessidade em desenvolver um jogo destinado a estimular as atividades voltadas para o ensino da leitura e escrita em crianças com dislexia. De maneira geral, na proposta do desenvolvimento de SE [Bazzo 1998] atenta-se para a necessidade de fornecer conexões individuais e coletivas, permitindo o desenvolvimento de projetos vinculados com a realidade dos alunos. Tais projetos devem integrar diferentes áreas do conhecimento, mídias digitais e sistemas tecnológicos, bem como a criação de espaços contextualizados com os objetivos propostos, em que o usuário dos sistemas possam manipular objetos tecnológicos virtuais e reais, e realizar experimentações, concretizando idéias e conceitos.

\section{Concepção do Jogo Educacional}

O principal resultado deste trabalho de pesquisa é portanto a concepção de um jogo educacional para alfabetização de crianças com dislexia. O desenvolvimento dessa concepção leva em conta os conceitos teóricos abordados nas seções anteriores. A concepção detalha a estrutura e o funcionamento do jogo que tem como propósito construir e desenvolver o processamento auditivo e a habilidade na consciência fonológica para ampliar os requisitos necessários no desenvolvimento da leitura e da escrita.

O jogo aqui denominado de "Os Niridianos no Inacreditável Mar de Letras" simula uma aventura de dois jovens que passavam férias em um cruzeiro próximo de uma cidade fictícia, "Nirídia", quando são surpreendidos pelo pirata "Barba-ruiva" que navegava pelo local. Em seguida, o pirata os convocou para realizar uma missão de recuperar seu tesouro perdido no fundo do "Mar de Letras". A aventura começa quando os dois jovens niridianos enfrentam perigos e lutam contra o tempo para desvendar os enigmas presentes no fundo do mar. A estrutura do jogo é dividida em três etapas, a saber: apresentação do jogo, estabelecimento das atividades relacionadas à leitura e a escrita e a finalização do jogo. Sendo que nessa etapa teremos seis fases definidas durante o processo e sequenciadas da forma a seguir:

- Etapa 1 - Apresentação do jogo;

- Etapa 2 - Estabelecimento das atividades relacionadas à leitura e a escrita

$\circ$ Fase 1 - Discriminar imagens;

- Fase 2 - Segmentar e reconhecer sons;

- Fase 3 - Segmentar e reconhecer rimas;

- Fase 4 - Discriminar fonemas;

- Fase 5 - Completar palavras;

- Fase 6 - Soletrar palavras.

- Etapa 3 - Finalização do jogo

As orientações do jogo relacionadas à execução são apresentadas na Etapa 1. Na Etapa 2 são sequenciadas as fases do jogo por etapa, ou seja, o usuário só avança para a próxima fase ao completar antecessora. Para cada fase serão apresentadas duas tarefas, nas quais o usuário pratica a coordenação motora, utilizando as setas do teclado para explorar as cavernas através do mergulho e a barra de espaço para recuperar o tesouro perdido. Após completar essas ações, o usuário finaliza a atividade através de um 
enigma a ser resolvido, sempre obedecendo a sequência de eventos da Etapa 2. Cada fase pretende trabalhar a concentração, a coordenação motora e, ao mesmo tempo, as atividades necessárias para trabalhar a leitura e a escrita. Após concluir todas as fases da Etapa 2, é iniciada a etapa de finalização do jogo, que fornece uma avaliação global do desempenho do aluno em todas as atividades executadas.

\subsection{Etapa 1 - Apresentação do jogo}

É apresentado nesta etapa o contexto do jogo, seus propósitos, objetivos e resultados de aprendizagem. Apresentando ao usuário informações relevantes para execução do jogo. Nesta etapa não são esperados resultados de aprendizagem, e da mesma forma não existe avaliação do aluno. Nesta etapa teremos o seguinte roteiro, demonstrado na tabela a seguir.

Tabela 2 - Roteiro da Etapa 1

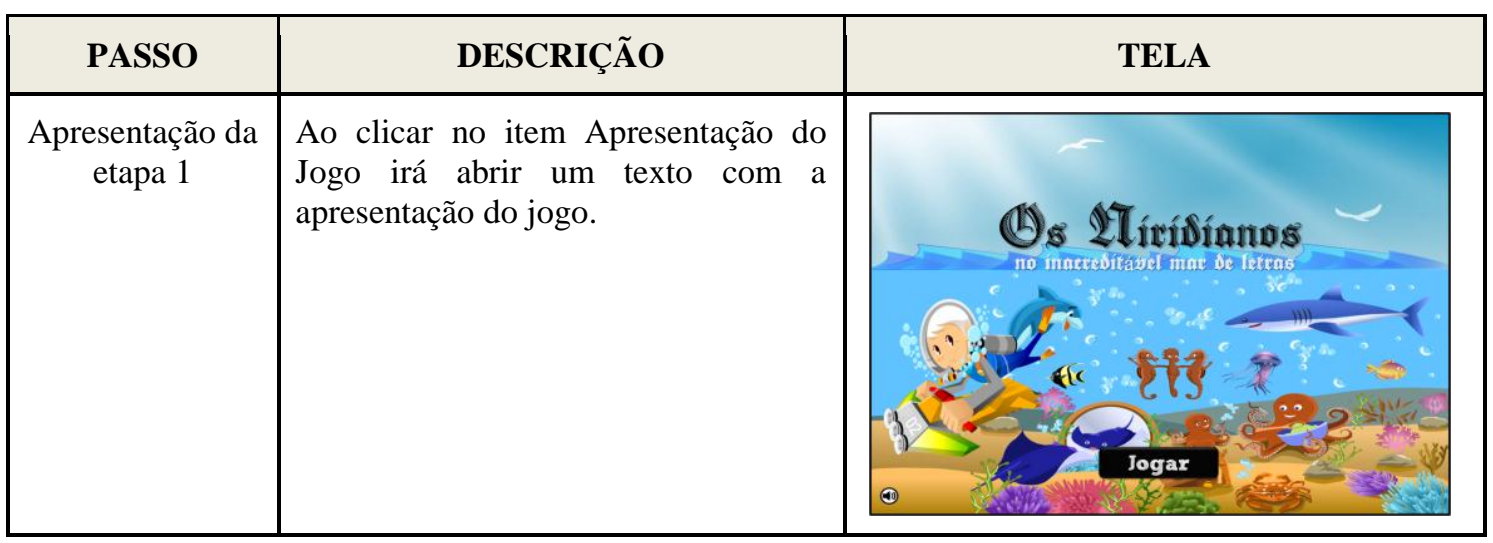

Fonte: Criado pelos autores (2014).

\subsection{Etapa 2 - Estabelecimento das atividades relacionada à leitura e a escrita}

Nesta etapa teremos o seguinte roteiro, demonstrado na tabela a seguir.

Tabela 3 - Roteiro da Etapa 2

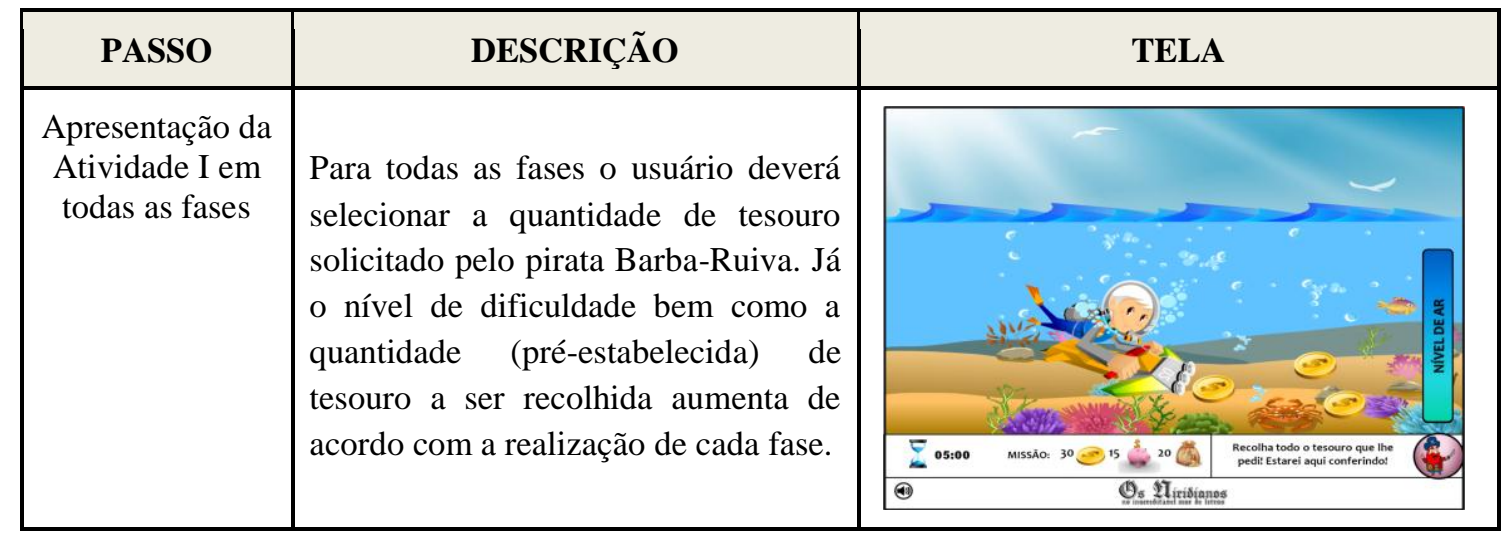




\begin{tabular}{|c|c|c|}
\hline $\begin{array}{c}\text { Apresentação da } \\
\text { Atividade II na } \\
\text { Fase I }\end{array}$ & $\begin{array}{l}\text { Permitir que o usuário identifique } \\
\text { qual das figuras apresentadas pelo } \\
\text { software é semelhante na forma, } \\
\text { tamanho, posição e orientação. Após } \\
\text { execução desta atividade espera-se } \\
\text { que o usuário aumente suas } \\
\text { habilidades de discriminar } \\
\text { formas/figuras iguais. }\end{array}$ & 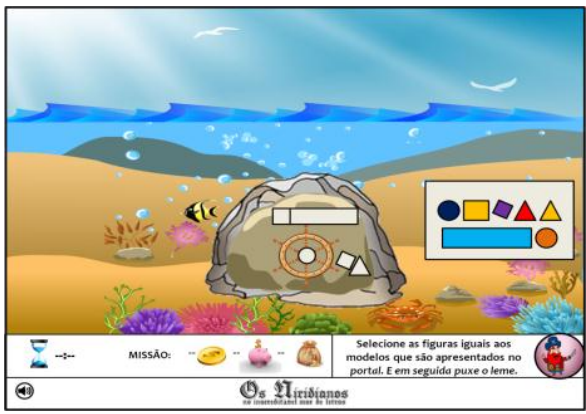 \\
\hline $\begin{array}{l}\text { Apresentação da } \\
\text { Atividade II na } \\
\text { Fase II }\end{array}$ & $\begin{array}{l}\text { Permitir que o usuário verifique } \\
\text { palavras e identifique qual delas } \\
\text { apresenta som diferente. Após a } \\
\text { execução desta atividade espera-se } \\
\text { que o usuário aumente suas } \\
\text { habilidades de segmentar palavra e } \\
\text { reconhecer sons diferentes. }\end{array}$ & 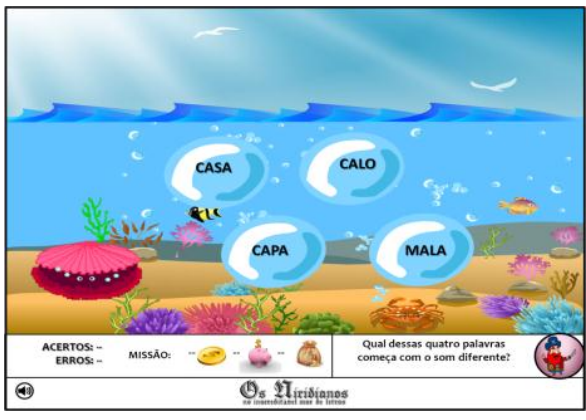 \\
\hline $\begin{array}{l}\text { Apresentação da } \\
\text { Atividade II na } \\
\text { Fase III }\end{array}$ & $\begin{array}{l}\text { Permitir que o usuário verifique } \\
\text { palavras e identifique qual delas } \\
\text { apresenta rima diferente. Após } \\
\text { execução desta atividade espera-se } \\
\text { que o usuário aumente suas } \\
\text { habilidades de segmentar palavra e } \\
\text { reconhecer rimas diferentes. }\end{array}$ & 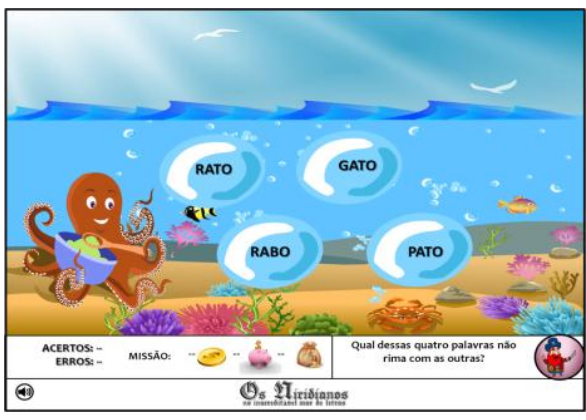 \\
\hline $\begin{array}{l}\text { Apresentação da } \\
\text { Atividade II na } \\
\text { Fase IV }\end{array}$ & $\begin{array}{l}\text { Permitir que o usuário discrimine } \\
\text { qual fonema difere entre as palavras } \\
\text { cujo som e grafia são próximas. Após } \\
\text { execução desta atividade espera-se } \\
\text { que o usuário aumente suas } \\
\text { habilidades de discriminar palavras a } \\
\text { partir dos fonemas, devendo } \\
\text { selecionar qual fonema as diferem. }\end{array}$ & 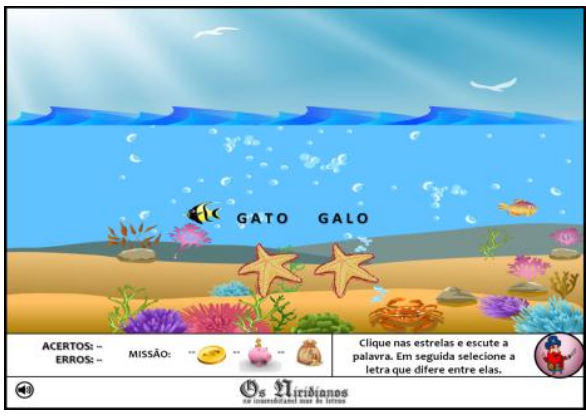 \\
\hline $\begin{array}{c}\text { Apresentação da } \\
\text { Atividade II na } \\
\text { Fase V }\end{array}$ & $\begin{array}{l}\text { Permitir que o usuário corresponda o } \\
\text { fonema que falta para formar } \\
\text { palavras. Após execução desta } \\
\text { atividade espera-se que o usuário } \\
\text { aumente suas habilidades de } \\
\text { corresponder fonemas que faltam } \\
\text { para formar palavras. }\end{array}$ & 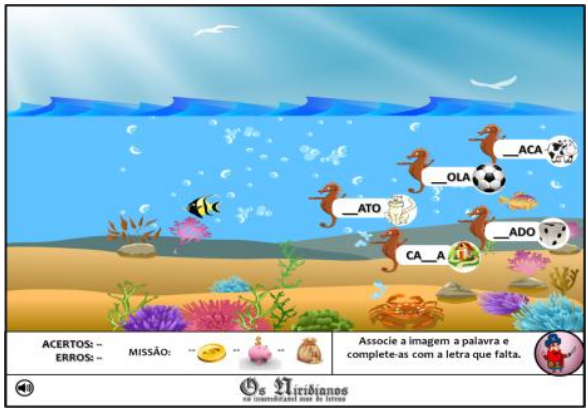 \\
\hline
\end{tabular}




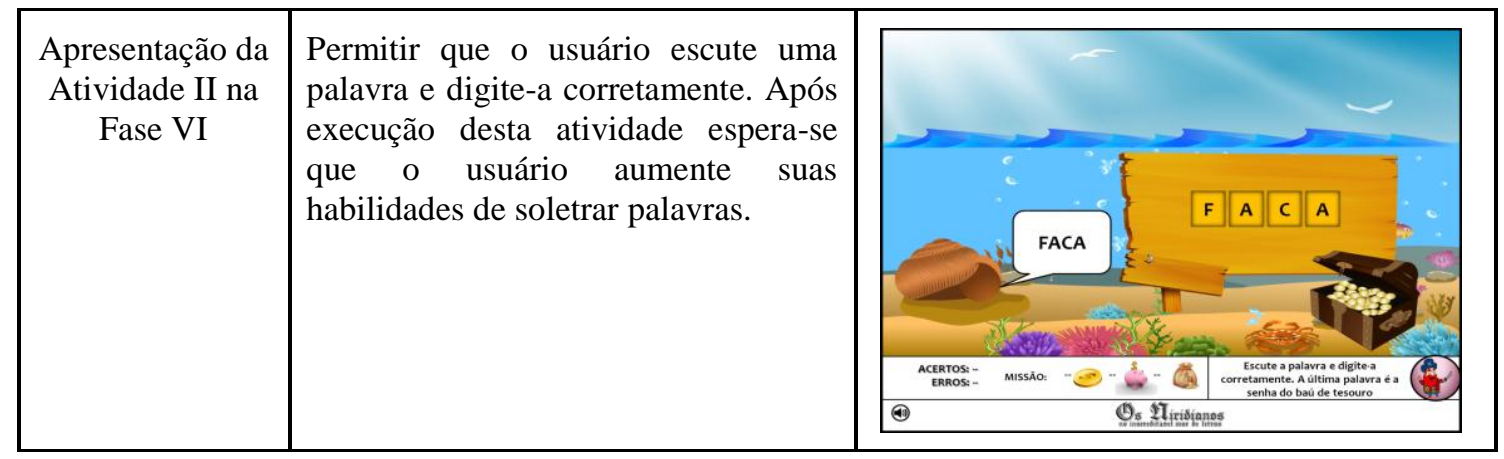

Fonte: Criado pelos autores (2014).

\subsection{Etapa 3 - Finalização do jogo}

Nesta etapa de finalização do jogo, será apresentado o desempenho global do jogador, com base nas decisões tomadas durante a execução das atividades. Serão utilizados dois critérios de avaliação: um relacionado ao tempo e o outro relacionado ao desenvolvimento do enigma. A pontuação do aluno ao final de cada fase será calculada com base no seu desempenho durante o jogo em função do tempo. Com relação a esse desempenho, o professor terá o feedback sobre uma determinada decisão tomada pelo aluno em cada tarefa e, em seguida, poderá prosseguir com a correção das respostas erradas.

O objetivo dessa etapa é apresentar de forma resumida ao usuário sobre seu desempenho ao longo da execução do jogo. Nesta etapa não são esperados resultados de aprendizagem e tão pouco existe uma avaliação. Após o término da atividade irá abrir um texto com a avaliação global do jogador.

\section{Considerações Finais}

Foi identificada a carência de mercado de softwares aptos para o apoio da leitura no disléxico, conforme relatado na seção 4 deste artigo, lacuna esta que motivou a realização deste trabalho, com o objetivo de desenvolver uma concepção de um jogo educacional para o ensino de crianças disléxicas na fase de alfabetização. A ideia é utilizar o aplicativo futuramente como uma ferramenta de apoio no processo de aquisição da leitura e da escrita. A proposta do jogo é melhorar a percepção audiovisual de um disléxico a partir de atividades lúdicas e de caráter educacional trabalhadas durante tal fase.

O principal resultado deste trabalho até o momento é a própria concepção do jogo desenvolvida para alfabetização de crianças dislexicas nas fases iniciais da escolarização. O jogo simulará diversos requisitos necessários para o desenvolvimento da leitura e escrita, em crianças de 6 a 12 anos. Além disso, é designado um diagrama de avaliação que admite que os resultados motivados pelo aluno e as deliberações tomadas por ele sejam considerados automaticamente e possibilite o feedback para o aluno. O jogo engloba 6 fases, incluindo atividades voltadas para leitura, a saber: discriminar imagens, segmentar e reconhecer sons, segmentar e reconhecer rimas, discriminar fonemas, completar palavras e soletrar palavras. A concepção especificada neste trabalho detalha a estrutura do funcionamento do jogo e sua avaliação, para que possa ser facilmente implementado no futuro. O impacto esperado é que o software promova o desenvolvimento da concentração e no aprimoramento do senso lógico, 
matemático e organizacional, exigindo muita atenção das crianças, melhorando a capacidade de combinar elementos e desenvolvendo habilidades em crianças nas mais diversas áreas do conhecimento.

Como trabalhos futuros, almeja-se que a concepção desenvolvida neste trabalho seja implementada e o SE seja usado como ferramenta que facilite o processo de ensinoaprendizagem de crianças disléxicas em atividades relacionadas a leitura e a escrita. Após sua implementação será verificado o impacto do software, se este promoveu de forma efetiva o desenvolvimento da concentração e no aprimoramento do senso lógico, matemático e organizacional das crianças. Assim, o desenvolvimento e a avaliação do software são os próximos passos dessa pesquisa.

\section{Referências}

Associação Brasileira de Dislexia. (2012). "Site da Associação Brasileira de Dislexia", http://www.dislexia.org.br, Julho.

Amaral, N. C.; Costa, P. C. (2011). "A informática como auxiliar no tratamento da dislexia". Em: Revista Cientifica Eletrônica de Pedagogia, Garça, SP, ano 9, n. 1, p. 2, Janeiro.

Bazzo, W. A. (1998). "Ciência, tecnologia e sociedade: e o contexto da educação tecnológica”. Florianópolis, Editora da Universidade Federal de Santa Catarina.

Capellini, S. A. (2004). "Distúrbios de aprendizagem versus dislexia". In: Ferreira, L. P.; Befi-Lopes, D. M.; Limongi, S. C. O. (Orgs.). Tratado de Fonoaudiologia. São Paulo: Roca.

Fletcher, J. M.; Lyons, G. R.; Fuchs, L. S.; Barnes, M. A. (2009). "Transtornos de Aprendizagem: da identificação à intervenção". Porto Alegre: Artmed Editora S.A.

Gil, A. C. (1991). “Como elaborar projetos de pesquisa”. São Paulo: Atlas.

Instituto ABCD. (2014). "Site do Instituto do ABCD". http://www.institutoabcd.org.br/portal/index.php, Janeiro.

Jung, C. F. (2014). "Metodologia Científica: ênfase em pesquisa tecnológica", http://www.jung.pro.br, Maio.

Pinto, I. M.; Botelho, S. C. (2012). “Ambientes Tecnológicos Lúdicos de Autoria (ATLA): uma proposta para potencialização dos processos de ensino e aprendizagem”. Em: Revista Brasileira de Informática na Educação, v. 20, n. 03.

Schirmer, C. R.; Fontoura, D. R.; Nunes, M. L. (2004). "Distúrbios da aquisição da linguagem e da aprendizagem". Em: Jornal de Pediatria, Rio de Janeiro, v. 80, n. 2, p. 95-103, Abril. http://www.scielo.br/pdf/jped/v80n2s0/v80n2Sa11.pdf, Novembro.

Silva, S. (2013). “Com a palavra, os gestores”. Revista Educação, São Paulo, SP, ano 17, n. 199 , p. 72 , nov.

Valente, J. A. (1999). “O computador na sociedade do conhecimento”. Em: Unicamp. Campinas.

Zorzi, J. L. (2011). "O que devemos saber a respeito da linguagem escrita e seus distúrbios: indo além da clínica". Em: Andrade, C. R. F.; Marcondes, E. (Org.), Fonoaudióloga em Pediatria. $1^{a}$ ed. São Paulo: Sarvier, 2003. p. 120-134. 